\title{
THE EFFECTS OF CREEP AND HYDRIDE ON SPENT FUEL INTEGRITY DURING INTERIM DRY STORAGE
}

\author{
HYUN-GIL KIM*, YONG-HWAN JEONG and KYU-TAE KIM ${ }^{1}$ \\ Nuclear Convergence Technology Division, Korea Atomic Energy Research Institute \\ 1045 Daedeokdaero, Yuseong-gu, Daejeon 305-353, Korea \\ ${ }^{1}$ Energy \& Environment System Eng. Dept. Dongguk University \\ 707, Seokjang-dong, Gyeongju, Gyeongbuk 780-714, Korea \\ ${ }^{*}$ Corresponding author. E-mail : hgkim@kaeri.re.kr
}

Received May 03, 2010

Recently, many utilities have considered interim dry storage of spent nuclear fuel as an option for increasing spent fuel storage capacity. Foreign nuclear regulatory committees have provided some regulatory and licensing requirements for relatively low- and medium-burned spent fuel with respect to the prevention of spent fuel degradation during transportation and interim dry storage. In the present study, the effect of cladding creep and hydride distribution on spent fuel degradation is reviewed and performance tests with high-burned Zircaloy-4 and advanced $\mathrm{Zr}$ alloy spent fuel are proposed to investigate the effect of burnup and cladding materials on the current regulatory and licensing requirements. Creep tests were also performed to investigate the effect of temperature and tensile hoop stress on hydride reorientation and subsequently to examine the temperature and stress limits against cladding material failure. It is found that the spent fuel failure is mainly caused by cladding creep rupture combined with mechanical strength degradation and hydride reorientation. Hydride reorientation from the circumferential to radial direction may reduce the critical stress intensity that accelerates radial crack propagation. The results of cladding creep tests at $400^{\circ} \mathrm{C}$ and $130 \mathrm{MPa}$ hoop stress performed in this study indicate that hydride reorientation may occur between $2.6 \%$ to $7.0 \%$ strain in tube diameter with a hydrogen content range of 40-120ppm. Therefore, it is concluded that hydride re-orientation behaviour is strongly correlated with the cladding creep-induced strain, which varies as functions of temperature and stress acting on the cladding.

KEYWORDS : Spent Nuclear Fuel, Interim Dry Storage, Cladding Creep, Temperature, Hoop Stress, Hydride Reorientation

\section{INTRODUCTION}

Many countries operating nuclear power plants have addressed how to dispose spent nuclear fuel without any hazard to mankind but they have not provided regulatory and licensing criteria for safe spent fuel disposal accepted by the public. Since many spent fuel pools at nuclear power plants throughout the world are near capacity, most utilities have to consider interim dry storage of spent fuel as an option for increasing spent fuel storage capacity. Therefore, the dry storage concept is becoming a major technical consideration for intermediate spent fuel storage at present [1]. In relation to this, studies on the effects of interim dry storage conditions on spent fuel integrity have recently been initiated in Korea.

The dry storage conditions necessary for maintaining spent fuel integrity may differ depending on the spent fuel storage operating conditions including normal and accident conditions. The dry cask storage conditions for spent fuel may be summarized as follows [2]:

- Long storage time: 40 years or more, e.g., 100 years
- Inert gas, helium storage atmosphere instead of pressurized or boiling water, as this will decrease heat transfer but generate no corrosion

- Decay heat that can raise the cladding temperature up to $400^{\circ} \mathrm{C}$ or higher at the beginning of the storage period and the temperature will thereafter decrease over time.

- Atmospheric storage pressure combined with high fuel temperature and internal gas pressure may result in high clad overpressure and subsequently high clad hoop stress, which will decrease with time as well.

- No external radiation

Fuel cladding failure during interim dry storage is mainly caused by cladding creep rupture and mechanical strength degradation combined with hydride reorientation, where these factors are in turn affected by cladding overpressure, fuel decay heat, and storage time [3]. Delayed hydride cracking (DHC) in zirconium alloy is also a possible degradation mechanism in interim dry storage [4]. The fuel cladding integrity during in-reactor operation depends on the amount of oxidation, irradiation hardening, 
and hydrogen pick-up. Therefore, these parameters have to be considered for the spent fuel cladding integrity. On the other hand, the maximum operating experience regarding wet storage of spent fuel is about 40 years, whereas that for dry storage is about 20 years. The spent fuel burnup in wet and dry storage is in a range of 33000 to $45,000 \mathrm{MWD} / \mathrm{MTU}$ (Batch Average Burnup). High burnup fuel and materials have already been developed and are currently being used in commercial nuclear power plants in order to enhance their economy. Therefore, it is expected that spent nuclear fuel burnup in the next 10 years will be in a range of 45,000 to 55,000MWD/MTU (Batch Average Burnup).

The aim of this work is to review the effects of cladding creep and hydride distribution on spent fuel degradation and to provide some key guidelines for regulatory and licensing requirements of high-burned spent fuel. Especially, creep research results were considered to investigate the effects of temperature and tensile hoop stress on hydride reorientation and subsequently to examine temperature and stress limits against cladding failure.

\section{REVIEW OF REGULATORY AND LICENSING REQUIREMENTS}

The most significant fuel design criteria for dry storage are listed in Table 1 [5]. Based on these regulatory and licensing requirements, the key cladding performance parameters include pellet-clad interface temperature, fuel burnup, cladding hoop stress, cladding strain, cladding creep, cladding oxidation, etc. The hoop stress limit combined with the temperature limit is used as a key regulatory requirement in most countries, because the stress limit can define the fuel cladding integrity clearly and easily. The strain limit has been eliminated in the USA, since it can be replaced by the stress limit. However, the strain limit is still utilized by some countries. Even though cladding creep rupture is considered to be the main failure mode and mechanism during interim dry storage, the creep rupture limit has not been used and has been replaced by the temperature and stress limits by most countries, with Spain being a notable exception. The cladding oxide thickness has not been used as a limit for the spent fuel integrity but it has been used to calculate the cladding metal thinning, a variable that is employed in the hoop stress calculation. Other potential failure mechanisms of the PWR cladding are stress corrosion cracking (SCC) and delayed hydride cracking (DHC). SCC was considered not to be active for spent fuel failure in interim dry storage, as the elemental iodine is insufficient to cause SCC. The threshold stress for the initiation of inter-granular cracking stresses is in a range of $180-200 \mathrm{MPa}$, which is not

Table 1. Comparison of International Dry Storage Regulations [5]

\begin{tabular}{|c|c|c|c|c|c|c|}
\hline Dry storage criteria & USA & Germany & Hungry & $\begin{array}{c}\text { S. Korea } \\
\text { (CANDU only) }\end{array}$ & Spain & Switzerland \\
\hline $\begin{array}{c}\text { Fuel-clad interface } \\
\text { temp. }{ }^{\circ} \mathrm{C} \\
\cdot \text { storage } \\
\cdot \text { drying }\end{array}$ & $\begin{array}{l}400 \\
570\end{array}$ & $\begin{array}{l}370 \\
370\end{array}$ & $\begin{array}{l}410 \\
410\end{array}$ & $\begin{array}{l}\text { None but } \\
\text { maintain clad } \\
\text { integrity }\end{array}$ & $\begin{array}{l}400 \\
570\end{array}$ & $\begin{array}{c}\text { None } \\
570\end{array}$ \\
\hline Burn-up, GWD/MT & None & $\begin{array}{l}65 \text { ave. } \\
\text { assembly }\end{array}$ & $49-50$ & None & None & None \\
\hline $\begin{array}{l}\text { Clad hoop stress, } \\
\qquad \mathrm{MPa}\end{array}$ & $\begin{array}{c}90 \\
\text { (suggested) }\end{array}$ & 120 at $370^{\circ} \mathrm{C}$ & None & None & 90 & $\begin{array}{c}120 \text { (PWR) } \\
90 \text { (BWR) }\end{array}$ \\
\hline Clad strain limit & None & $1 \%$ circum. & None & None & $\begin{array}{l}1 \% \text { for high } \\
\text { burn-up }\end{array}$ & $\begin{array}{c}1 \% \text { during } \\
\text { storage }\end{array}$ \\
\hline $\begin{array}{l}\text { Creep rupture } \\
\text { limits }\end{array}$ & None & None & None & None & $\begin{array}{l}\text { Limited by }{ }^{\circ} \mathrm{T} \\
\text { and stress limit }\end{array}$ & None \\
\hline $\begin{array}{l}\text { Cladding condition } \\
\text { limit }\end{array}$ & $\begin{array}{l}\text { Oxide thickness } \\
\text { for stress cal. }\end{array}$ & $\begin{array}{l}\text { Oxide thickness } \\
\text { for stress cal. }\end{array}$ & None & None & $\begin{array}{l}\text { Limited by }{ }^{\circ} \mathrm{T} \\
\text { and stress limit }\end{array}$ & None \\
\hline $\begin{array}{l}\text { Failed fuel } \\
\text { definition }\end{array}$ & $\begin{array}{c}\text { USNRC ISG1, } \\
\text { rev. } 2\end{array}$ & $\begin{array}{l}\text { Any assembly } \\
\text { with defected } \\
\text { rods }\end{array}$ & $\begin{array}{c}\text { Failed assembly } \\
\text { identified by } \\
\text { shipping }\end{array}$ & $\begin{array}{c}\text { Clad } \\
\text { penetration that } \\
\text { emits fission } \\
\text { products }\end{array}$ & $\begin{array}{l}\text { NRC ISG1, } \\
\text { rev. } 1\end{array}$ & None \\
\hline
\end{tabular}


achievable even for high burnup fuel. In addition, hydride has no relation with iodine-induced SCC. However, DHC cannot be ruled out for spent fuel failure, and DHC modelling has recently been carried out to simulate the crack growth mechanism [4].

According to the fuel related regulatory requirement criteria of Rev.3 in the USA [2], the items that should be considered for the cladding with respect to the transportation and storage of spent fuel are:

- A $400^{\circ} \mathrm{C}\left(752^{\circ} \mathrm{F}\right)$ maximum cladding temperature must be maintained for normal storage conditions including drying, backfilling, and transfer operations.

- Higher temperatures may be justified for short periods of time for fuel with $<45 \mathrm{GWD} / \mathrm{MT}$ burnup if the hoop stresses do not exceed $90 \mathrm{MPa}$ at temperature (the $90 \mathrm{MPa}$ limit does not apply at $400^{\circ} \mathrm{C}$ of below at any burnup).

- Cladding stress should be based on the effective cladding thickness after corrections for oxide thickness and hydride rims.

- For off-normal and accident conditions the cladding temperature should not exceed $570^{\circ} \mathrm{C}$.

- Temperature cycling that may, as an example, occur during loading operations must be limited to $<\Delta 65^{\circ} \mathrm{C}$ and for 10 cycles.

- Effects of transportation accidents on cladding integrity, particularly the effects of high hydrogen concentrations,

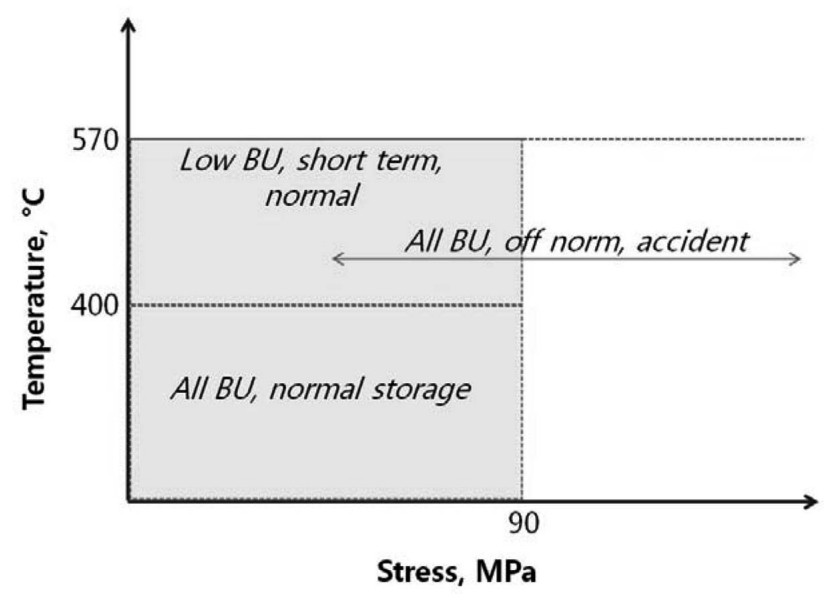

Fig. 1. Cladding Regulation Limits for Dry Storage in the USA [6]

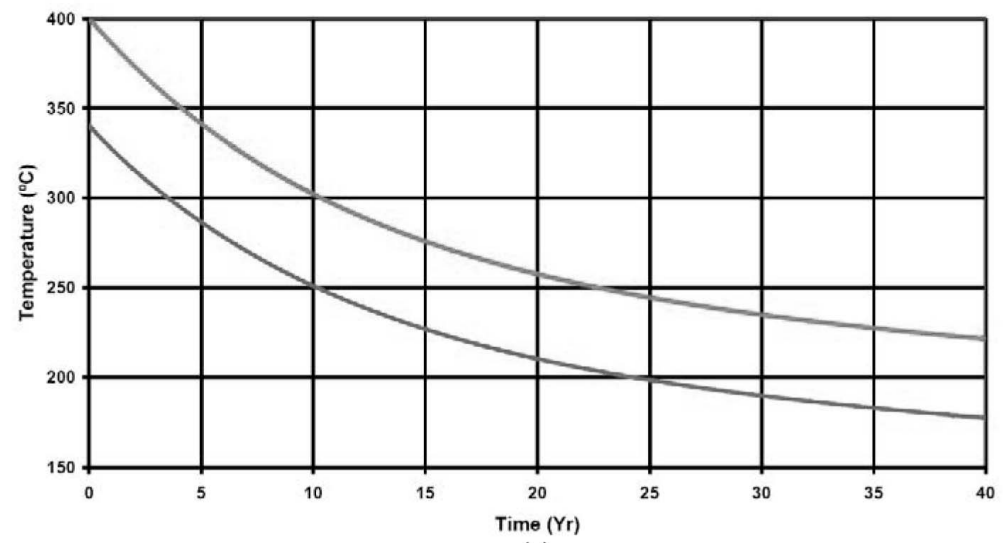

(a)

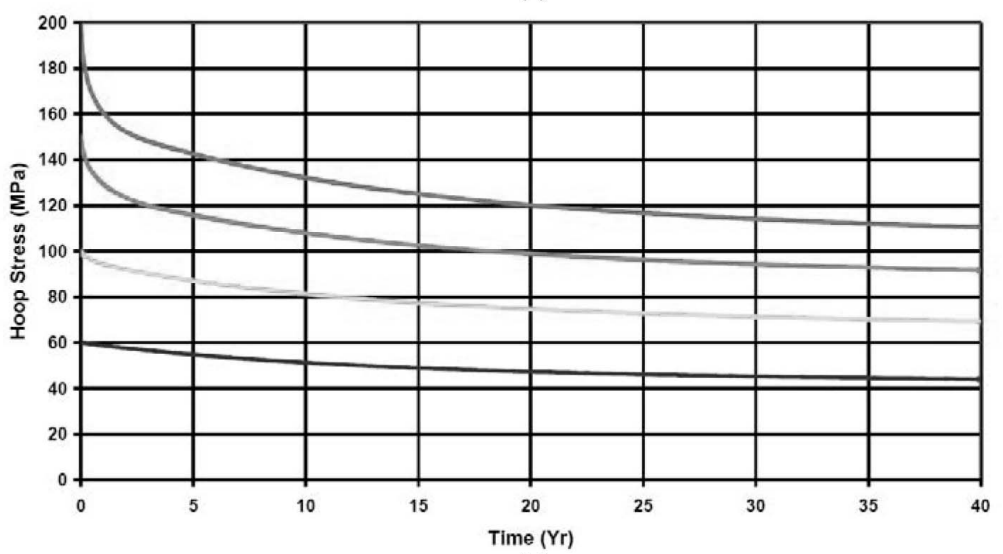

(b)

Fig. 2. 40-year Temperature History of Spent Fuel Cladding in Dry Storage Cask (a) and Hoop Stress Histories for an Initial Temperature of $400^{\circ} \mathrm{C}$ (b) [7] 
are currently being evaluated and license applications will be reviewed on a case by case basis until an ISG (Interim Staff Guidance) can be issued in the future.

The temperature and stress limits can be adjusted to prevent creep rupture-induced failure. The amount of hydride reorientation may be taken into account to reduce the temperature and stress limits, since it will accelerate creep rupture and subsequently reduce fuel failure time. Note that the NRC is considering the effect of radial hydrides on fuel failure occurring during handling and transportation accidents The NRC has recognized that some design limit medications including the stress limit are needed in addition to Rev. 3 [6] as follows:

- 90MPa cladding hoop stress limit should be applied at temperature at all burnups, but if an applicant has data and analysis to justify higher stress limits the case will be evaluated on its merits.

- $570^{\circ} \mathrm{C}$ maximum cladding temperature for all short term operations with low burnup ( $<45 \mathrm{GWD} / \mathrm{MTU})$ fuel

- An inert gas cask atmosphere for storage and transportation

- A reflood analysis to assure sub-criticality with water moderation during handling and transport accidents

The limits for the cladding integrity recommended by NRC are shown in Fig. 1 as a function of stress and temperature. For dry cask storage, the cladding temperature can reach several hundred degrees as a result of the fuel decay heat. The sources of internal pressure are He gas pre-pressurization during fuel fabrication, fission gases, and alpha decay of $\mathrm{Pu}$ isotopes in the fuel during storage
[2]. All of these pressurization sources are burnup dependant except pre-pressurization. The internal pressure of cladding during dry storage is further raised by the fuel decay heat. Therefore, creep deformation of the fuel cladding will continue to occur due to the increase in the internal pressure during dry storage. The cladding temperature and internal gas pressure are highest at the early stage, and decrease with exposure time in dry storage, as shown in Fig. 2 [7]. In addition, hydride reorientation may occur if a sufficient hoop stress combined with temperature exists during interim dry storage, since cladding containing a hydrogen level of 100-600ppm is exposed to a relatively high temperature and hoop stress for a lengthy period. The effect of hydride orientation, i.e., radial and circumferential hydrides, on the mechanical behaviours of un-irradiated cladding has previously been studied [8]. It was reported that samples with radial hydrides failed in a more brittle manner than samples with circumferential hydrides despite that the hydrogen content of the samples was the same, as shown in Fig. 3. Therefore, it can be concluded that cladding having radial hydrides is undesirable for the handling and transportation of the spent fuel assembly.

\section{REVIEW OF CLADDING CREEP BEHAVIOR DURING DRY STORAGE}

Creep behaviour of Zr-based alloys is affected by such factors as chemical composition, texture, and micro-

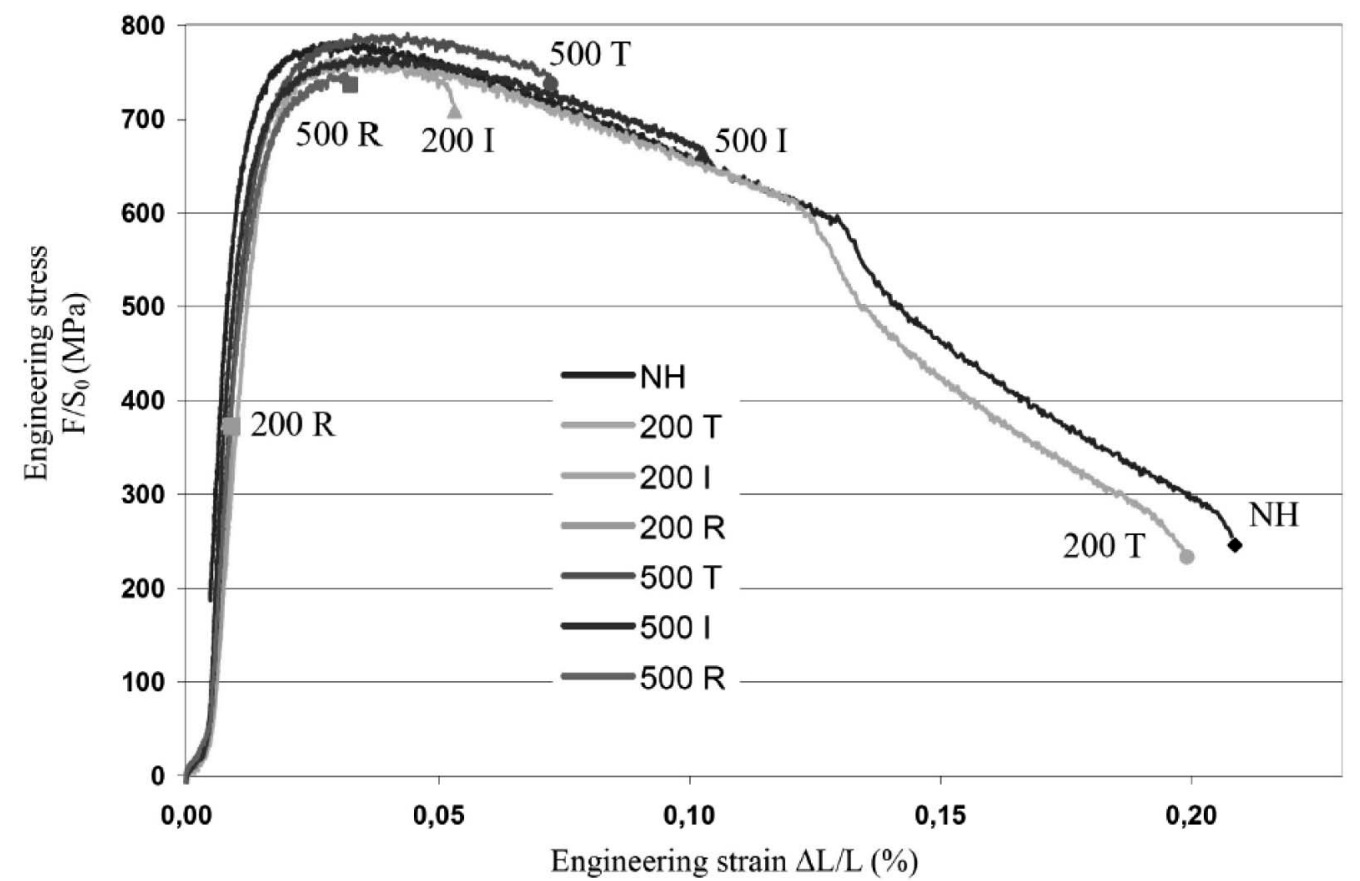

Fig. 3. Load Normalized with the Initial Section-strain Curve; NH: None Hydride, 200 and 500: Hydrogen Content of 200ppm and 500ppm, T: Tangential Hydride Orientation, R: Radial Hydride Orientation, I: Intermediate Hydride Orientation [8] 
structural characteristics of grain size and dislocation density. The creep mechanism of Zr-based alloys is controlled by the test temperature and applied stress [9]. Considering that the cladding creep direction is outward, creep-rupture is the most likely cladding failure mode during dry storage. Since there is no irradiation during dry storage, ex-reactor creep tests can give valid results for the cladding creep modelling of spent fuel.

The main parameters that control creep rupture are the cladding temperature and stress level. Creep behaviour with stress and temperature was evaluated by using the recrystallized Zircaloy-4 strip test [10]. Since creep tests were carried out under a constant load stress in a temperature range from 350 to $450^{\circ} \mathrm{C}$ and a stress range from 110 to $230 \mathrm{MPa}$, the obtained data are suitable to consider the creep behaviour of Zircaloy-4 in dry storage conditions. From the results of the aforementioned previous study of creep for Zircaloy-4 strip, shown in Fig. 4, the creep deformation was increased by increasing the applied stress as well as by increasing the test temperature. From this figure, it is found that abrupt changes in the creep strain are related to the test temperature. The creep strain is considerably increased by applied stress from 200MPa to $230 \mathrm{MPa}$ in the $350^{\circ} \mathrm{C}$ test, whereas it increases from $140 \mathrm{MPa}$ to $170 \mathrm{MPa}$ in the $400^{\circ} \mathrm{C}$ test, and from $110 \mathrm{MPa}$ to $140 \mathrm{MPa}$ in the $450^{\circ} \mathrm{C}$ test. At the same stress of $140 \mathrm{MPa}$, the creep strain rate is sharply increased by increasing the test temperature from $400^{\circ} \mathrm{C}$ to $450^{\circ} \mathrm{C}$. From these results, it is concluded that the creep property of Zircaloy-4 material is dependent on the stress and temperature level. A transition of creep rate with the applied strain is observed in a test temperature range of 350 to $450^{\circ} \mathrm{C}$.

When compared to the cladding stress limit for dry storage, shown in Fig. 1, the stress limit of 90MPa up to $400^{\circ} \mathrm{C}$ is acceptable in terms of avoiding excessive creep strain in Zircaloy-4 cladding. However, (what exactly?) is unknown for the stress limit of $90 \mathrm{MPa}$ up to $570^{\circ} \mathrm{C}$, because the creep strain increases exponentially with an increase of temperature. The recommended stress limit of $90 \mathrm{MPa}$ is still under debate, because a typical hoop stress at the initial storage temperature is in the range of 60 to $120 \mathrm{MPa}$.

The creep kinetics with hydrogen content should also
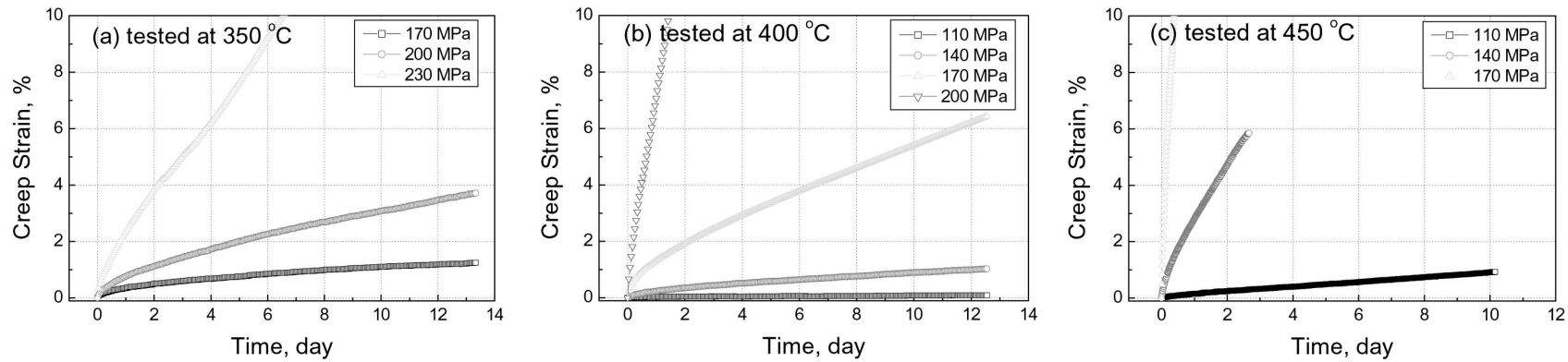

Fig. 4. Creep Behaviour of Zircaloy-4 Strip with Different Test Temperature and Applied Stress

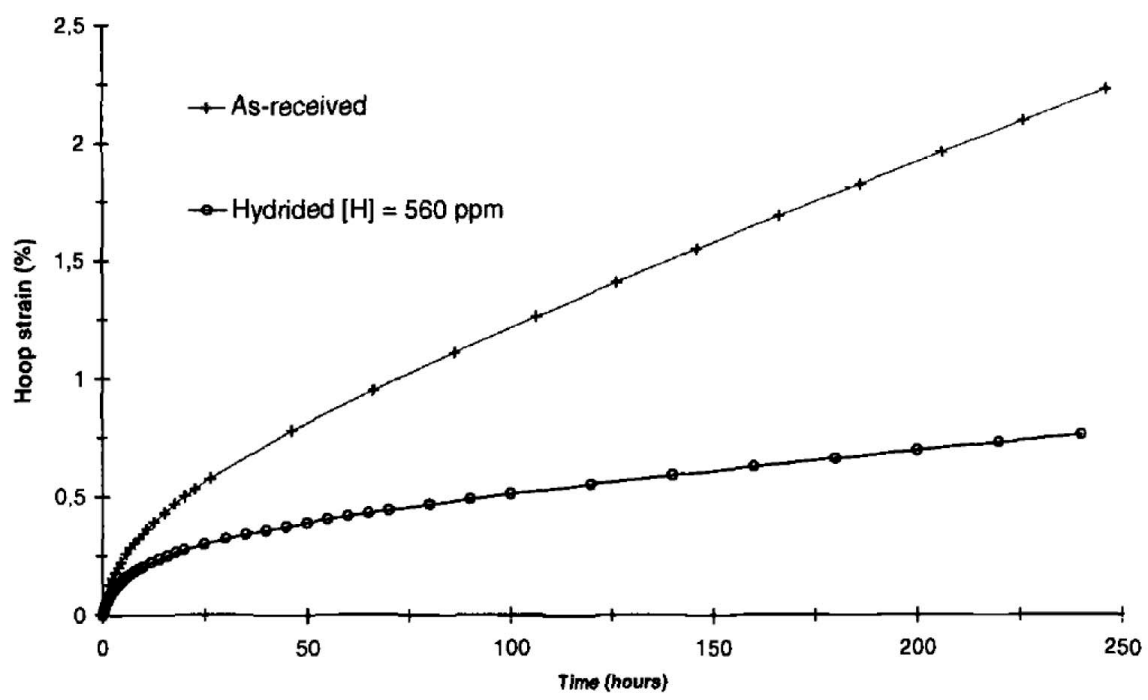

Fig. 5. Biaxial Creep at $400^{\circ} \mathrm{C} / 140 \mathrm{MPa}$ - Hoop Strain Versus Time [11] 
be considered, because high burn-up cladding contains hydrogen and hydrides as a result of oxidation processes during in-reactor operation. It has been reported that hydrogen in the form of hydrides reduces static recovery [11]. Through this mechanism, the presence of hydrides in the cladding will help prevent the cold work microstructure from being annealed out of dislocations and thereby maintain lower creep rates in the spent fuel cladding, as shown in Fig. 5 [11].

In order to make a cladding tube creep model for interim dry storage, therefore, it is necessary to study the detailed correlations among creep strain (up to rupture time of cladding tube), temperature, and hydrogen content. Because Korea has not yet provided regulations or licensing limits for interim dry storage such as peak clad temperature, internal pressure, strain limit, etc., it is recommended that a systematic creep study related to the cladding integrity be performed as soon as possible.

\section{STUDY ON HYDRIDE REORIENTATION OF CLADDING DURING DRY STORAGE}

The NRC has recognized that the fuel cladding integrity is reduced by hydride reorientation from the circumferential to radial direction. The radial hydrides appear to reduce the critical stress intensity required to propagate a radial crack in the cladding during handling or transportation [8]. The effects of hoop stress and temperature on hydride reorientation are shown in Fig. 6. The stress limits for hydride reorientation appear to decrease with an increase of temperature. The stress limit of $90 \mathrm{MPa}$ at $400^{\circ} \mathrm{C}$, used as a regulatory and licensing requirement, is shown in this figure.

Another type of hydride related degradation of spent fuel cladding is DHC. The potential of DHC to cause cladding degradation is taken into account in Chao's model [4]. His model confirmed that crack propagation increases as the amount of hydride reorientation from the circumferential to radial direction increases. In general, radial hydrides in zirconium alloy cladding are not common, since the texture of the zirconium alloy cladding is controlled during the tube manufacturing process to generate circumferential hydrides. It has been reported that the hydrides can reorient in the radial direction if the cladding is exposed to sufficient tensile or hoop stress at a higher temperature [12].

However, it is necessary the tube creep test to utilize the strain effect on hydride reorientation, because the creep strain effect in a dry storage environment has not been studied. The tube creep study using a cladding comprised of $\mathrm{Zr}-1 \mathrm{Nb}-1 \mathrm{Sn}-0.1 \mathrm{Fe}$ [13] could be quotated to discuss the strain effet on hydride orientation. The tube has dimensions of $200 \mathrm{~mm}$ length, $9.5 \mathrm{~mm}$ outer diameter, and $0.57 \mathrm{~mm}$

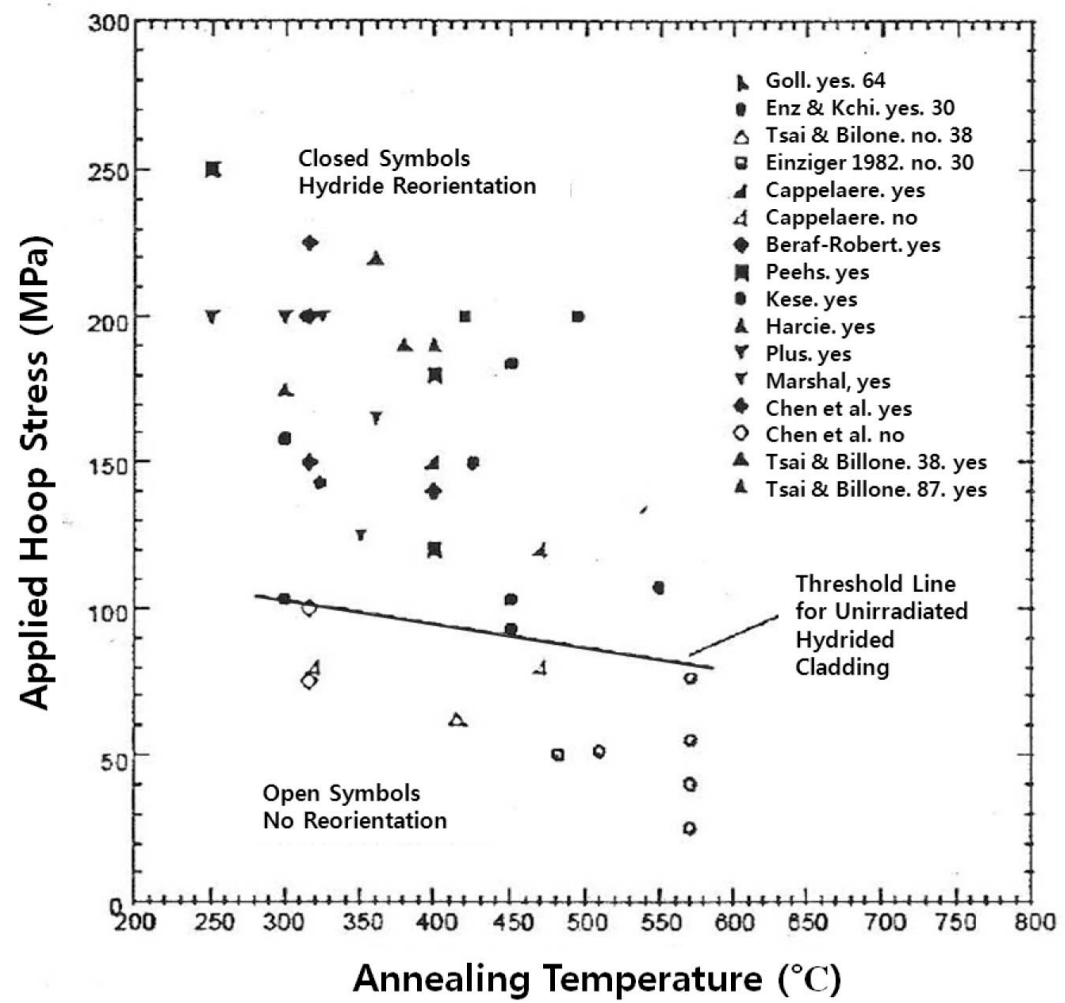

Fig. 6. NRC Evaluation of Hydride Re-orientation with Applied Hoop Stress as Function of Isothermal Annealing Temperature [6] 
wall thickness. A tube creep test apparatus, wherein the internal pressure and the test temperature can be controlled, was used to obtain the creep deformation behaviour. The medium for internal pressure was argon as an inert gas, and the internal pressure was calculated by the thin walled tube equation given below.

$$
\sigma_{\theta}=\mathrm{PD}_{\mathrm{m}} / 2 \mathrm{w}
$$

where $\sigma_{\theta}$ is the tube hoop stress, $\mathrm{P}$ is the internal pressure, $\mathrm{D}_{\mathrm{m}}$ is the tube mid-wall diameter, and $\mathrm{w}$ is the tube wall thickness. The test temperature and hoop stress were $400^{\circ} \mathrm{C}$ and $130 \mathrm{MPa}$, respectively. The diameter change by creep deformation was measured using a micrometer with $10^{-2} \mathrm{~mm}$ resolution after 5 and 20 day tests for two samples. To identify the correlation between creep strain and hydride reorientation, microstructural observation was performed using a scanning electron microscope (SEM, JEOL 6300). Although hydrogen was not charged in the test rod before the creep test, hydrogen up-take was found to occur during the creep test at $400^{\circ} \mathrm{C}$ in an air condition. A hydrogen analysis was performed using 2-3 $\mathrm{mm}$ sections cut from the crept rod samples using a vacuum fusion method (LECO RH-404).

Fig. 7 shows the hoop creep strain and hydrogen content of the $\mathrm{Zr}-1 \mathrm{Nb}-1 \mathrm{Sn}-0.1 \mathrm{Fe}$ alloy cladding tube as a function of test time. The hoop strain was measured as $2.6 \%$ for the 5 day test and $7.0 \%$ for the 20 day test. The hydrogen content was analyzed to be $40 \mathrm{ppm}$ for the 5 day test and $120 \mathrm{ppm}$ for the 20 day test. Fig. 8 shows the hydride morphologies before and after the creep tests. To identify the hydride morphology and direction, microstructural observations were performed for the axial normal plane.

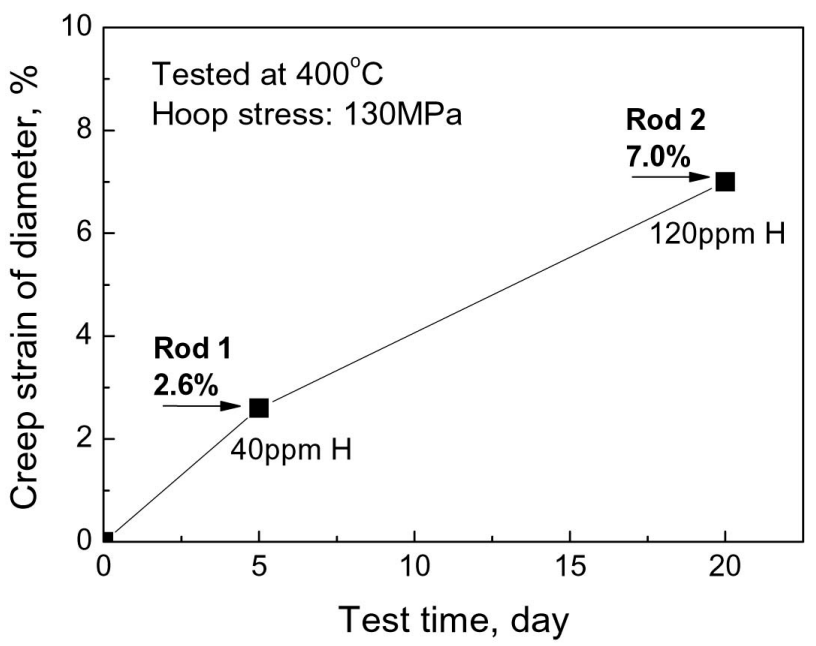

Fig. 7. Hoop Creep Strain and Hydrogen Uptake Content of Zr$1 \mathrm{Nb}-1 \mathrm{Sn}-0.1 \mathrm{Fe}$ Tube as a Function of Test Time
Before the creep test, no hydride was formed in the cladding, from the outer to inner surface. Hydrides were observed in the $2.6 \%$ strained sample and their orientation was parallel to the hoop direction, whereas the hydride orientation in the $7.0 \%$ strained sample was in both the hoop and radial directions into halves. From this result, it is found that hydride reorientation occurred with strain ranging from $2.6 \%$ to $7.0 \%$ in tube diameter with a hydrogen content range of $40-120 \mathrm{ppm}$. Considering that the results of this work are very limited, an extensive study on the effects of strain and temperature at different hoop stress on hydride reorientation is necessary.

Other hydride reorientation tests using Zircaloy-4 in a cold worked or SRA state with 100 to $600 \mathrm{ppm}$ hydrogen levels were also performed $[14,15]$. The results indicated that hydride reorientation may occur due to applied stress, heat cycling (cool-down rate), and temperature factors. Because hydride reorientation is a diffusion process that occurs in a dry storage environment for up to 40 years, the strain effect identified in this work will continue to affect hydride related degradation of cladding materials. In addition, the advanced PWR alloy ZIRLO showed low hydrogen pick-up during in-reactor operation when compared to Zircaloy-4. Therefore, the condition of low hydrogen content will be studied in the future.

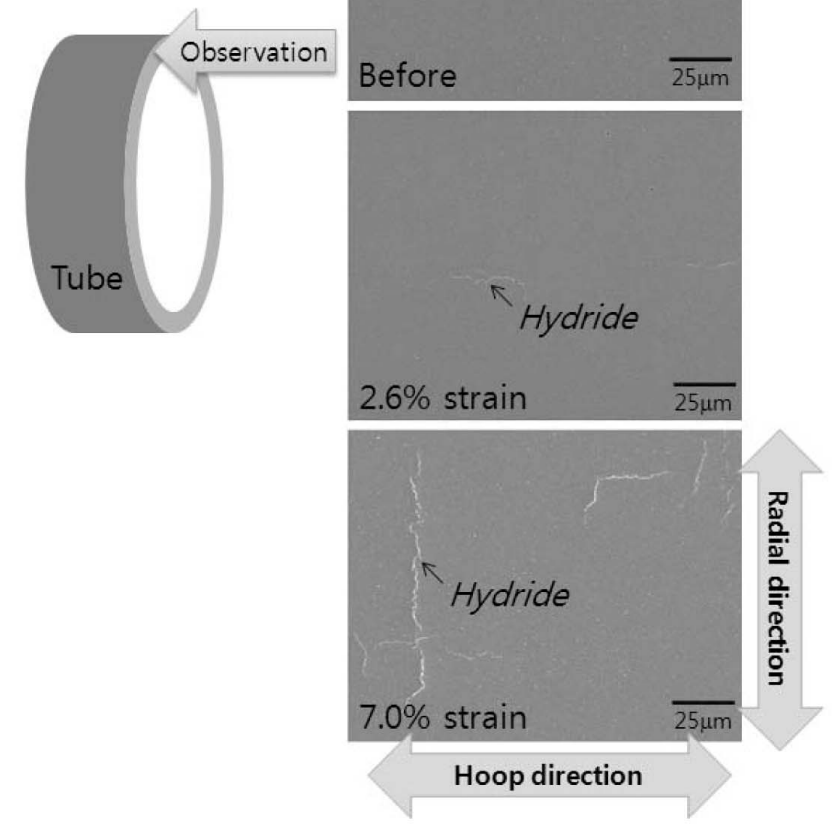

Fig. 8. SEM Observation of the Hydride Morphology in Samples before and after Creep Test 


\section{EFFECT OF HIGH BURNUP AND CLADDING MATERIALS ON SPENT FUEL INTEGRITY}

As shown in Fig. 9 [16], discharged fuel burnup is continuously increasing. In Korea, the batch average burnup employed in in-reactor operation was about $33,000 \mathrm{MWD} / \mathrm{MTU}$ in the $1970 \mathrm{~s}, 38,000 \mathrm{MWD} / \mathrm{MTU}$ in the $1980 \mathrm{~s}$, and recently increased to $45,000 \mathrm{MWD} / \mathrm{MTU}$. Furthermore, it is expected that the discharged fuel burnup will reach $55,000 \mathrm{MWD} / \mathrm{MTU}$ if the RIA issue is resolved. The maximum dry storage experience is about 20 years, with the use of a batch average burnup of 38,000MWD/MTU and Zircaloy-4 cladding. However, the discharged fuel burnup with Zirclaoy-4 or advanced $\mathrm{Zr}$ alloys, e.g., ZIRLO and M5, will be increased to $45,000 \mathrm{MWD} / \mathrm{MTU}$ or more in the next 10 years. It is well known that Zircaloy-4 oxidation is accelerated above about 40,000MWD/MTU, and consequently cladding metal thinning is also accelerated. Meanwhile, advanced $\mathrm{Zr}$ alloy oxidation is substantially less than Zirclaoy-4 oxidation and cladding metal thinning of the former, even at high burnup, is approximately the same as Zirclaoy-4 metal thinning at $40,000 \mathrm{MWD} / \mathrm{MTU}$. However, fission gas release and decay heat will be accelerated with an increase of discharged burnup regardless of the cladding materials. This means that the cladding hoop stress and decay heat of high burned spent fuel cladding will sharply increase as compared to the current spent fuel cladding in interim dry storage. In other words, the maximum cladding hoop stress and achievable temperature for high-burned spent fuel are much greater than those for the current spent fuel in interim dry storage.

Table 2 summarizes cladding failure mechanisms of spent fuel in interim dry storage. From this table, it can be seen that DHC, hydride reorientation-induced failure, and hydride rim-induced failure are relatively unimportant for advanced $\mathrm{Zr}$ alloys, since these alloys undergo much less oxidation than Zircaloy-4 and subsequently much less hydride. To investigate the effects of high-burned spent fuel with Zircaloy-4 cladding or advanced $\mathrm{Zr}$ alloys on failure limits, including the stress and temperature limits, it is thus strongly recommended that the following

Table 2. Cladding Failure Mechanisms of High Burned Zircaloy-4 and Advanced Zr Alloys in Interim Dry Storage

\begin{tabular}{l|c|c}
\hline \multicolumn{1}{c|}{ Failure mechanism } & Zircaloy-4 & $\begin{array}{c}\text { Advanced } \\
\text { Zr alloy }\end{array}$ \\
\hline High temperature creep rupture & $\mathrm{O}$ & $\mathrm{O}$ \\
\hline Delayed hydride cracking & $\mathrm{O}$ & $\Delta$ \\
\hline Hydride reorientation-induced failure & $\mathrm{O}$ & $\Delta$ \\
\hline Embrittlement-induced failure & $\mathrm{O}$ & $\mathrm{O}$ \\
\hline Hydride rim-induced failure & $\mathrm{O}$ & $\Delta$ \\
\hline
\end{tabular}

$\mathrm{O}$ : Strong Failure Mechanism, $\Delta$ : Mild Failure Mechanism

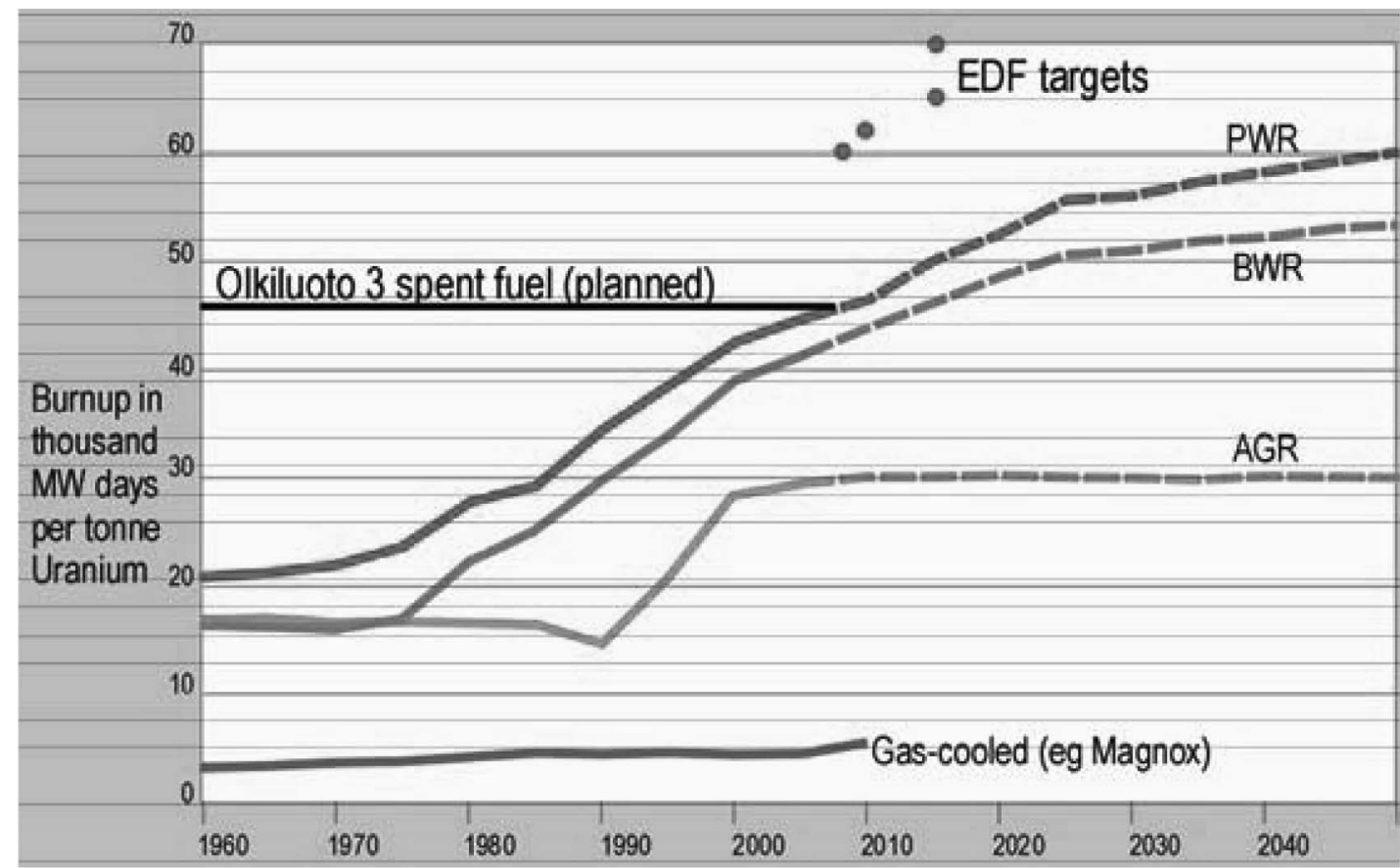

Fig. 9. Discharged Fuel Burnup History and Prospect [15] 
performance degradation tests be performed:

- Select Zirclaoy-4 fuel rods and advanced Zr alloy rods (HANA, ZIRLO, M5) with discharged fuel burnup of $45,000,50,000,55,000$, and 60,000MWD/MTU

- Select basic performance data through hot-cell nondestructive and destructive tests using the above fuel rods

- Remove fuel pellets from the fuel rods and prepare cladding tube specimens

- Perform mechanical tests, high temperature creep tests, DHC tests, hydride rim-induced failure tests, and embrittlement-induced failure tests using the cladding tube specimens at anticipated temperature and hoop stress for high-burned spent fuel

- Consider inert gas and air as dry storage environments

- Based on the test results, evaluate stress limits, temperature limits, and other failure limits for highburned Zircaloy-4 and advanced $\mathrm{Zr}$ alloy spent fuel

\section{SUMMARY}

Based on wide ranging investigations on interim dry storage conditions and relevant failure modes, it is found that the key cladding performance parameters are cladding temperature, fuel burnup, cladding hoop stress, cladding strain, cladding creep, and cladding oxidation. The hoop stress limit combined with the temperature limit is used as a key regulatory requirement in most countries, because the stress limit can clearly define the fuel cladding integrity. The strain limit has been eliminated in the USA, since it can be replaced by the stress limit. However, the strain limit is still utilized by some nations. Fuel cladding failure may be caused by creep-rupture and mechanical strength degradation combined with hydride reorientation. According to the spent fuel related regulatory and licensing requirement criteria of Rev. 3 provided by the NRC in the USA, the major limiting parameters for dry storage are $400^{\circ} \mathrm{C}$ cladding maximum temperature and $90 \mathrm{MPa}$ cladding hoop stress, which are based on the hydride reorientation behaviour from the circumferential to radial direction. Radial hydrides in zirconium cladding are undesirable, because they reduce the critical stress value required to propagate a radial crack through the cladding wall during handling or interim dry storage.

Cladding tube creep tests were performed in this study to investigate the strain effect on hydride reorientation. The results of the creep tests indicated that hydride reorientation occurred between $2.6 \%$ to $7.0 \%$ strain in the tube diameter. Considering that the results of this work are very limited, an extensive study on the effects of strain and temperature at different hoop stresses on hydride reorientation is necessary.

With an increase of burnup, fuel performance parameters such as fission gas release, cladding oxidation, and fuel decay heat will be sharply increased. Consequently, the cladding hoop stress and temperature of high burned spent fuel cladding are sharply increased, compared to the current low- and medium-burned spent fuel cladding used in interim dry storage. With the use of high burned Zircaloy-4 and advanced $\mathrm{Zr}$ alloys, therefore, it is strongly recommended that various cladding tube degradation tests such as mechanical tests, high temperature creep tests, DHC tests, hydride rim-induced failure tests, and embrittlementinduced failure tests be performed.

\section{ACKNOWLEDGMENTS}

This study was conducted under the auspices of the Nuclear R\&D program run by the Ministry of Education, Science and Technology (MEST).

\section{REFERENCES}

[1 ] K.S. Bang, J.C. Lee, K.S. Seo, C.H. Cho, S.J. Lee and J.M. Kim, "Heat Removal Test using a Half Scale Storage Cask", J. Nucl. Sci. \& Tech. Vol. 39 (2) 159 (2007).

[2 ] U.S. Code of Federal Regulations, "Licensing Requirements for the Independent Storage of Spent Nuclear Fuel and High-level Radioactive Waste", Part 72, Title 10, Energy (2005).

[ 3 ] M. Peehs and J. Fleisch, "LWR Spent Fuel Storage Behaviour", J. Nucl. Mater. 137, 190 (1986)

[4 ] C.K. Chao, K.C. Yang, C.C. Tseng, "Rupture of Spent Fuel Zircaloy Cladding in Dry Storage due to Delayed Hydride Cracking", Nucl. Eng \& Design, 238, 124 (2008).

[5] Advanced Nuclear Technology International Europe AB, ANT International, 9-12 (2008)

[6 ] R. Einziger, C. Brown, G. Horneth, and C. Interrante, "Data Needs for Storage and Transportation of High-Burnup Fuel", Radwaste Solutions, Apr. (2005)

[ 7 ] J. Rashid, A. Machiles, "Threat of Hydride Re-orientation to Spent Fuel Integrity During Transportation Accidents: Myth or Reality?", Int. LWR Fuel Performance Meeting, ANS, San Francisco, California, Oct. (2007)

[8] A. Racine, M. Bornert, D. Caldenmaison, C.C. Sainte, and C. Cappelaere, "Experimental Investigation of Strain, Damage and Failure of Hydrided Zircaloy-4 with Various Hydrides Orientations", Proc. $18^{\text {th }}$ International Conference in Structural Mechanics in Reactor Technology, SMiRT 18-C04-6, Beijing, China, Aug. 7-12 (2005)

[9] K.L. Murty, J.R. Wiratmo, "Transitions in creep mechanisms a creep anisotropy in $\mathrm{Zr}-1 \mathrm{Nb}-1 \mathrm{Sn}-0.2 \mathrm{Fe}$ sheet", Nucl. Eng. \& Design, 156, 359 (1995).

[10] H.G. Kim, B.K. Choi, Y.H. Jeong, "Evaluation of the thermal creep behaviors and microstructure of Zircaloy-4 strip", Nucl. Eng. \& Design, 238, 3331 (2008).

[11] P. Bouffioux, and N. Rupa, "Impact of Hydrogen on Plasticity and Creep of Unirradiated Zircaloy-4 Cladding Tubes", Zirconium in the Nuclear Industry, ASTM STP 1354, 399 (2000).

[12] K. Sakamoto, H. Matsuoka, and S. Kashibe, "Study in Hydride Reorientation in Zry-2 Fuel Cladding During Interim Dry Storage", Int. LWR Fuel Performance Meeting, ANS, San Francisco, Oct. (2007)

[13] H.G. Kim, I.H. Kim, S.Y. Park, J.Y. Park, Y.H. Jeong, 
"Evaluation of Hydride Effect on Fuel Cladding Degradation", Kor. J. Met. Mater. to be published.

[14] H.C. Chu, S.K. Wu, K.F. Chien, R.C. Kuo, "Effect of radial hydrides in the axial and hoop mechanical properties of Zircaloy-4 cladding”, J. Nucl. Mater. 362, 93 (2007).
[15] C. Cappelaere, R. Limon, et al., "Mechanical behaviour of the fuel cladding in dry storage during long term interim storage”, LECI Seminar, CEA, Saclay, France, Sep. (2006).

[16] Y.A. Sokolov, Status of nuclear power: A global view IAEA, GLOBAL 2005 9-13 Tsukuba, Japan, Oct. (2005). 